\title{
PERENCANAAN MAHAKAM BOUTIQUE HOTEL DI SAMARINDA PENEKANAN PADA TATA RUANG DALAM
}

\author{
Nur Husniah Thamrin \\ Staff Pengajar Jurusan Desain, Program Studi. Arsitektur, \\ Politeknik Negeri Samarinda \\ Email :nhusniah62@gmail.com \\ Hatta Musthafa Adham Putra \\ Staff Pengajar Jurusan Desain Program Studi. Arsitektur, \\ Politeknik Negeri Samarinda \\ Email : hattamusthafa@gmail.com \\ Paskalis \\ Mahasiswa Jurusan Desain, Program Studi. Arsitektur, \\ Politeknik Negeri Samarinda \\ Email : paskalisatta@gmail.com
}

\begin{abstract}
ABSTRAK
Samarinda merupakan ibu kota Kalimantan Timur, yang mempunyai jumlah penduduk lebih padat dari kota-kota yang berada di Kalimantan Kimur, segala kegiatan seperti kegiatan ekonomi, pendidikan maupun bisnis terpusat di Samarinda, dengan demikian Samarinda juga mempunya posisi yang strategis membangun bisnis dalam bidang jasa dan pelayanan sperti hotel, dimana pada umumnya Samarinda mempunyai sangat banyak jasa dan pelayanan hotel yang umum-umum saja, maka dari itu penulis mencoba merancang sebuah hotel, dimana hotel tersebut menyediakan pelayanan yang super eksklusif, serta mencoba menggunakan gaya bangunan vernakular Lamin Dayak yang merupakan rumah tinggal khas suku Dayak dan merupakan etnis setempat, yang bertujuan agar memperkuat brand kota Samarinda.

Dengan demikian Samarinda akan sedikit memberikan kesan yang bermanfaat bagi setiap pengunjung lokal maupun mancanegara yang datang dalam rangka kegiatan ekonomi, bisnis maupun pendidikan dengan adanya ketersediaan fasilitas tempat inap yang dirancang oleh penulis yaitu Mahakam Boutique Hotel.
\end{abstract}

Kata Kunci : Boutique, Vernakular, Lamin, Dayak, Hotel, Eksklusif. 
Nur Husniah Thamrin, Hatta Musthafa Adham Putra, Paskalis, Perencanaan Mahakam Boutique Hotel di Samarinda Penekanan Pada Tata Ruang Dalam

\section{ABSTRACT}

Samarinda is the capital of East Borneo, which has a denser population of cities in East Borneo, all activities such as economic, educational and business activities are concentrated in Samarinda, thus Samarinda also has a strategic position to build business in the field of services and Services such as hotels, where in general Samarinda have a lot of services and hotel services are general are only course, therefore the author tries to design a hotel, where the hotel provides super exclusiv services, and try to use the style of vernacular building Lamin Dayak, which is a residence Typical of Dayak tribe and is a local ethnic, which aims to strengthen the brand city of Samarinda.

Thus Samarinda will give a little impression that is beneficial for every visitor both local and foreign who come in the framework of economic activities, business and education with the availability of facilities inpatient designed by the author of Mahakam Boutique Hotel.

Keyword : Vernacular, Lamin, Dayak, Boutique, Hotel, Exclusive.

\section{PENDAHULUAN}

Kota Samarinda merupakan ibu kota provinsi Kalimantan Timur, Indonesia serta salah satu kota terbesar di Kalimantan. Seluruh wilayah kota ini berbatasan langsung dengan Kabupaten Kutai Kartanegara. Kota Samarinda dapat dicapai dengan perjalanan darat, laut dan udara. Dengan Sungai Mahakam yang membelah di tengah Kota Samarinda, yang menjadi "gerbang" menuju pedalaman Kalimantan Timur. Kota ini memiliki luas wilayah 718 kilometer persegi dan berpenduduk 805.688 jiwa pada tahun 2013 (Badan Pusat Statistik Kota Samarinda), menjadikan kota ini berpenduduk terbesar di seluruh Kalimantan. Dengan jumlah penduduk yang cukup tinggi serta salah satu kota yang merupakan akses menuju daerah pedalaman dan akses menujuh kota wisata, kota Samarinda sangat berpotensi sebagai kota persinggahan Tourist lokal maupun mancanegara atau bisa dikatakan sebagai kota yang harus memiliki konsep Transit Oriented Development (TOD). Disisi lain kota Samarinda sebagai kota perdagangan serta memiliki potensi jual beli yang cukup tinggi, baik di bidang pertanian, perkebunan, perternakan, perikanan, industri, parawisata, jasa serta bisnis di bidang perhotelan. Dari sekian banyak kegiatan bisnis di atas penulis dapat mengambil kesimpulan bahwa bisnis di bidang perhotelan sangatlah menjanjikan suatu kes4 uksesan besar yang dapat dilihat dari potensi dan posisi kota Samarinda karena begitu banyak kegiatan bisnis, hotel merupakan salah satu fasilitas yang sangat dibutuhkan pembisnis baik sebagai sarana tempat inap, rapat, pertemuan bisnis, perencanaan bisnis dan sebagainya, semua kegiatan yang menyangkut bisnis bisa dilakukan di hotel, baik bisnis antar warga negara lokal maupun mancanegara. (Wikimedia, 2017)

Dengan demikian Samarinda yang juga merupakan pusat pemerintahan juga bisnis baik di sektor tambang, struktur dan infrastruktur sehingga hal tersebut menjadi landasan dirancangnya, Boutique Hotel yang diperuntukan bagi pembisnis, pejabat pemerintahan kalangan umum dengan ekonomi menengah ke atas.

Perumusan masalah adalah bagaimana merancang Boutique Hotel dengan bangunan terdiri dari tiga lantai dan Penekanan pada Tata Ruang dalam serta menggunakan gaya Arsitektur Vernakular Lamin Dayak.

\section{METODE}

Metode pengumpulan data merupakan prosedur sistematis secara langsung dan tidak langsung terkait dengan tujuan untuk memperkuat ide dasar dari perancangan objek serta fungsi dari objek yang akan dirancang itu sendiri. Metode pengumpulan data ini terdiri dari dua macam, yaitu data primer 
Vol. 5, No. 2, April 2018

dan data skunder. Data primer merupakan data dari hasil survey penulis serta penjajakan langsungn ke sumber yang terkait. Sedangkan data sekuder merupakan data yang diperoleh penulis secara tidak langsung, tetapi dikumpulkan oleh orang lain, dan diolah kembali oleh penulis.

Data primer merupakan data yang diperoleh langsung oleh penulis. Dalam perancangan Boutique Hotel Penekanan pada Tata Ruang Dalam. Penulis menggunakan dua metode pengumpulan data secara primer, yaitu secara survey lapangan dan dokumentasi

Survey lapangan dengan mendatangi objek atau lokasi tapak secara langsung. Dengan tujuan untuk menganalisa faktor-faktor yang terkait dengan proses perancangan objek. Dengan melakukan survey lapangan ini akan dapat mengidentifikasi informasi-informasi mengenai kondisi existing tapak, kondisi lingkungan sekitar, potensi-potensi yang mampu mendukung fungsi dan objek rancangan dan juga dapat megidentifikasi permasalahan yang ada di lokasi. Dari hasil survey lapangan tersebut maka dapat di analisis dan menjadi bahan acuan untuk proses perancangan.

Dokumentasi, alam survey lapangan tersebut menggunakan media dokumentasi, dengan cara mengumpulkan dokumen-dokumen yang terkait dengan proses pencarian data sehingga di hasilkan informasi-informasi serta bukti yang kongkrit. Dalam perancangan Boutique Hotel di Samarinda Penekanan pada Tata Ruang Dalam : metode dokumenasi digunakan untuk. Mendokumentasikan kondisi rinci existing tapak yang terlah ditetapkan sebagai site project yang terletak dibagian sekitar kota Samarinda. Mendokumentasikan kondisi alam atau lingkunagan yang ada di sekitar tapak guna memperkuat prinsip dari konsep (TRD) Tata Ruang Dalam.

Data sekunder merupakan metode pengumpulan data yang tidak langsung, dalam arti penulis tidak langsung mendatangi dan menganalisis secara peribadi, melaink- an dari data orang lain yang diolah kembali oleh penuis, dikaitkan dengan permasalahan yang dipecahkan.

Dalam perancangan Boutique Hotel studi pustaka dimanfaatkan untuk pencarian data yang berkaitan dengan informasi yang terkait dengan kawasan dan tapak yang telah ditetapkan oleh badan Bappeda kota Samarinda. Kemudian dari data yang didapat tersebut akan dijadikan bahan pertimbangan proses perancangan. Pencarian literatur tentang hotel secara umum, dan segala macam jenis hotel menurut kelasifikasinya. Kemudian dari data yang didapat tersebut digunakan sebagai bahan analisis penentuan kebutuhan ruang yang yang akan dirancang pada objek Boutique Hotel.

Pencarian literatur mengenai "Konsep Tata Ruang Dalam" digunakan sebagai acuan dalam perancangan dengan menelaah prinsip-prinsip yang ada pada konesp tersebut kemudian diterapkan pada objek rancangan, sehingga tercipta objek rancangan yang memiliki karakter "Tata Ruang Dalam".

Metode pengelolaan data dapat diperoleh dari pengamat dan wawancara secara langsung dengan orang-orang yang berkaitan di dalamnya. Dalam pengamatan juga harus di tunjukan dengan adanya pengumpulan dokumentasi sehingga data-data yang diperoleh terbukti valid. Selain itu studi literatur juga di lakukan sebagai tambahan dalam pengumpulan data, sehingga sesuai dengan ketentuan dan ketetapan yang ada sesuai objek perancangan. Dalam proses pengumpulan data ini dapat dilakukan beberapa metode, antara lain sebagai berikut.

Pengamatan atau observasi dapat dilakukan langsung diantara masyarakat lingkungan kawasan sekitar kota Samarinda, sehingga mengetahui pengaruh-pengaruh sosial maupun pengaruh terhadap lingkungan sekitar dalam proses perancangan Boutique Hotel. dalam pengamatan atau observasi yang dialkukan ada beberapa data yang harus diperole yaitu, ukuran 
Nur Husniah Thamrin, Hatta Musthafa Adham Putra, Paskalis, Perencanaan Mahakam Boutique Hotel di Samarinda Penekanan Pada Tata Ruang Dalam

tapak perancangan maksimal $3.000 \mathrm{~m}^{2}$, batas tapak terhadap kawasan sekitar, suasana tapak di kawasan sekitar kota Samarinda yang berdasarkan kondisi iklim, dan letak geografis yang meliputi, arah peredaran dan radiasi matahari, kesilauan, kecepatan dan arah pergerakan angin, temperatur dan perubahan temperatur, kelembaban udara, curah hujan, kondisi dan topografi tanah serta data-data lain yang berhubungan dengan keadaan iklim dan geografis tapak.

Kondisi vegetaasi pada tapak kawasan sekitar kota Samarinda, kondisi keadaan sarana dan prasarana pada tapak perancangan di kawasan sekitar kota Samarinda, kondisi transportasi secara umum yang meliputi, jalur dan besaran jalan, angkutan dan pengguna jalan serta fasilitas pendukung lainya, kondisi umum ekonomi dan sosial masyarakat sekitar, kondisi drainase pada tapak perancangan.

Dokumentasi adalah pengumpulan data yang identik dengan pengambilan foto suatu objek observasi disekitar kawasan kota Samarinda. Namun disamping itu dapat juga berupa dokumen yang terkait dengan data-data yang dimiliki instansi pemerintah terkait, misalnya, denah kontur tapak, denah kawasan, dan sebagainya.

Data pada studi literatur ini dapat diperoleh dari teori, pendapat para ahli, saat peraturan dan kebijakan pemerintah yang akan mejadi dasar perancangan sehinga dapat memperdalam analisis.

Data yang diperoleh dari penelusuran literatur biasa bersumber dari data, internet, buku, brosur/pamflet, dan aturan kebijakan pemerintah. Adapun data-data itu meliputi, data atau literatur tentang tapak yaitu kawaasan kota Samarinda, yang berupa peta wilayah, potensi alam ataupun batuan yang terdapat di kawasan kota Samarinda. Data ini selanjutnya digunakan untuk menganalisis tapak, literatur tentang bangunan yang sehat dengan pemanfaatan iklim serta yang mendukung konsep "Penekanan pada Tata Ruang Dalam" sebagai gambaran dalam penerapan perancangan Boutique
Hotel, literatur tentang hotel yang meliputi pengertian, dan persyaratan hotel sebagai pertimbangan dalam menentukan golongan serta kelasifikasi kelas hotel, Literatur tentang Boutique Hotel yang meliputi pengertian, Jenis-jenisnya, faktor penyebab, dan prinsip desain sebagai gambaran dalam merancang Boutique Hotel dengan baik dan benar.

Studi banding merupakan perbandingan bangunan yang ada dengan literatur, sehingga mengetahui kesalahan-kesalahan dan keunggulan dari rancangan bangunan tersebut yang dapat menjadi acuan dalam perancangan Boutique Hotel. Data yang diambil dari studi ini berupa denah lokasi, organisasi ruang, foto-foto keadaan lokasi, mengamati situasi sekitar dan kapasitas pengunjung hotel mesra. Pada studi banding terdiri dari dua yaitu, studi bidang objek dan studi banding konsep. Pada studi banding objek dicari objek yang sama atau mendekati yaitu Hote Mesra, sedangkan pada studi banding konsep sejenis, namun bangunan tidak harus berupa hotel seperti Guesthouse.

\section{PEMBAHASAN}

3.1. Analisis Peruangan

Tujuanya ialah agar mengetahui daerah private, Service, Semi Private serta Public pada setiap ruangan Mahakam Boutique Hotel.

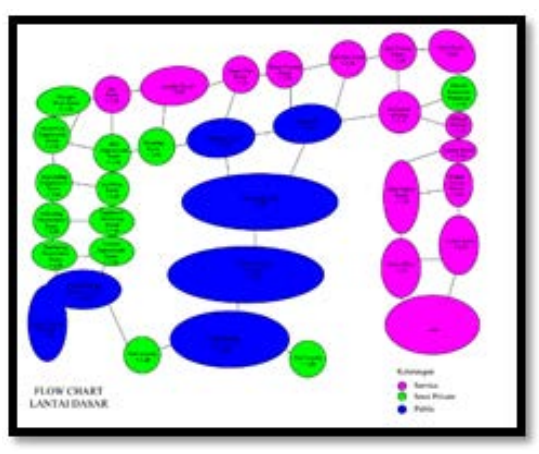

Gambar 1

Analisis Penzoningan Lantai Dasar (Sumber : Penulis, 2017) 
Di bagian lantai dasar akan diletakan ruangan-ruangan kantor pengelola yaitu, di bagian kiri arah hadap bangunan yang merupakan akses pintu masuk bagi karyawan hotel dan dibagian kanan arah hadap banguanan akan diletakan bagian kegiatan seperti, cafe, salon, spa, sauna, fitness, shopping dan merupakan arah pintu masuk tamu atau pengunjung yang bertujuan agar kegiatan tamu tidak terganggu oleh kegiatan karyawan hotel.

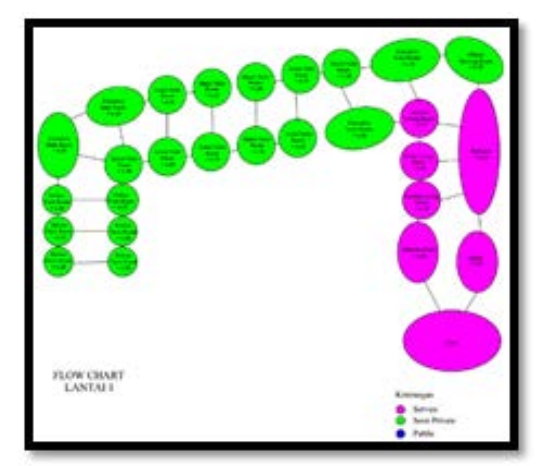

Gambar 2

Analisis Penzoningan Lantai 1 (Sumber : Penulis, 2017)

Di bagian lantai satu akan diletakan berbagai kegiatan yang steril bagi para tamu atau pengunjung seperti kegiatan inap dan sholat, yang bertujuan agar para pengunjung dapat menikmati pemandangan di sekitar luar site hotel baik view dari luar maupun dari dalam site.

Konsep seperti ini sangat nyaman bagi para pengunjung karena proses pencahayaan dan penghawan alami sangat maksimal berada di bagian lantai satu serta akses menuju lantai dua tidak terlalu sulit di capai oleh pengunjung apabila rekan pengunjung berada di lantai dua. Ruangan yang akan diletakan di lantai satu seperti, ruang inap, ruang penerimaan tamu, ruang kesehatan, ruang rapat dan ruang acara.

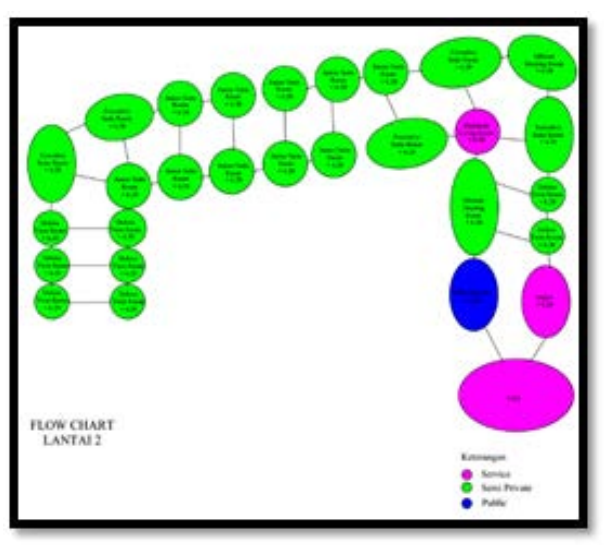

Gambar 3

Analisis Penzoningan Lantai 2

(Sumber : Penulis, 2017)

Di bagian latai dua tidak terlalu jauh berbeda dengan lantai satu karena penempatan jenis ruang yang sama yaitu ruang inap, ruang rapat, ruang penerimaan tamu.

\subsection{Konsep Bangunan}

Tujuanya ialah agar mengetahui gaya bangunan yang penulis gunakan dan beberapa aksesories pada perancangan fasad bangunan. 
Nur Husniah Thamrin, Hatta Musthafa Adham Putra, Paskalis, Perencanaan Mahakam Boutique Hotel di Samarinda Penekanan Pada Tata Ruang Dalam

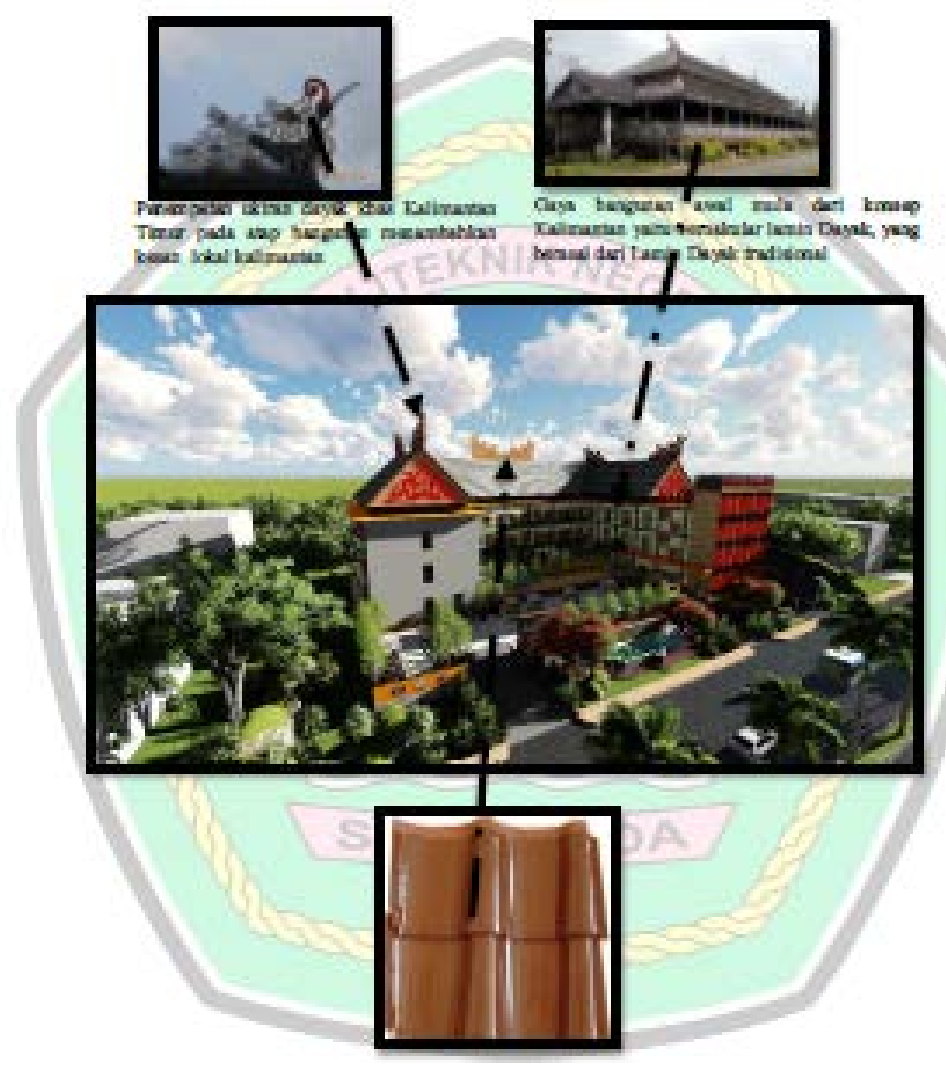

Penggunaan penutup atap bangunan menggunakan genteng kramik yang biasanya digunakan pada rumah tradisional Jawa.

Gambar 4. Konsep Bangunan

(Sumber : Penulis, 2017)

\subsection{Konsep Utilitas}

Konsep Utilitas Transportasi Vertikal

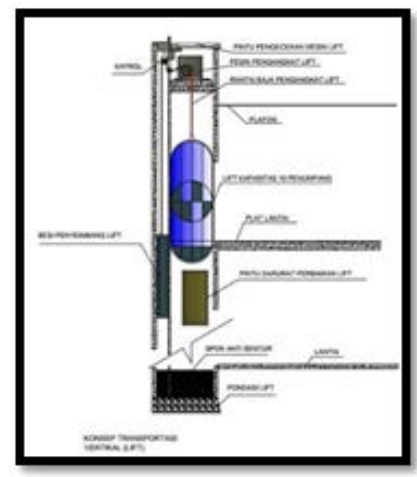

Gambar 5

Konsep Utilitas Transportasi Vertikal

(Sumber : Penulis, 2017)
Konsep transportasi vertikal yaitu menggunakan lift kapsul dan mesin lift diletakan di bagian atas bangunan dan bagian bawah diletakan spons anti bentur yang akan mengurangi bentur bila terjadi gagal lift akibat beban yang berlebihan pada saat rumah lift terjatuh atau putus. 
Vol. 5, No. 2, April 2018

Konsep Utilitas Air Panas Alami

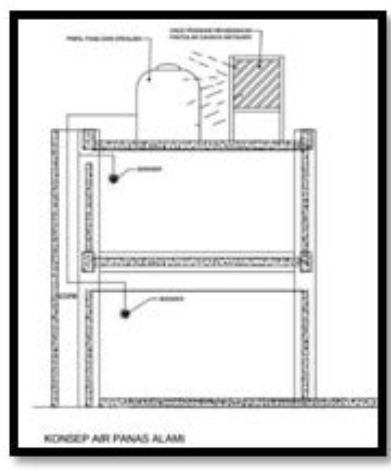

Gambar 6

Konsep Utilitas Air Panas Alami

(Sumber : Penulis, 2017)

Konsep air panas alami dengan cara menempatkan profil tank yang berbahan dasar stainless di atas atap balkon dan disinari menggunakan kaca melalui pantulan sinar matahari pada saat siang hari apabila cuaca cerah.

\section{Konsep Utilitas Penghawaan Buatan}

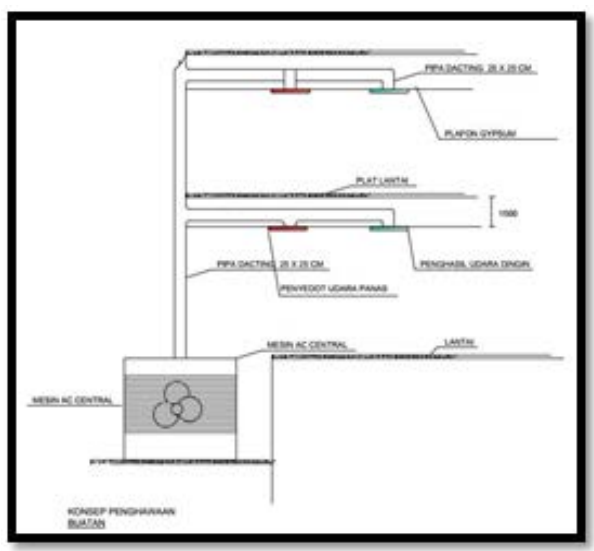

Gambar 7

Konsep Utilitas Penghawaan Buatan

(Sumber : Paskalis, 2017)

Konsep utilitas penghawaan buatan yaitu menggunakan Ac Central yang bertujuan agar memaksimalkan kontrol penghawaan di setiap ruangan dan juga tidak merusak fasad bangunan seperti Ac Split yang diletakan pada fasad bangunan.
Konsep Utilitas Hydrant Dinding

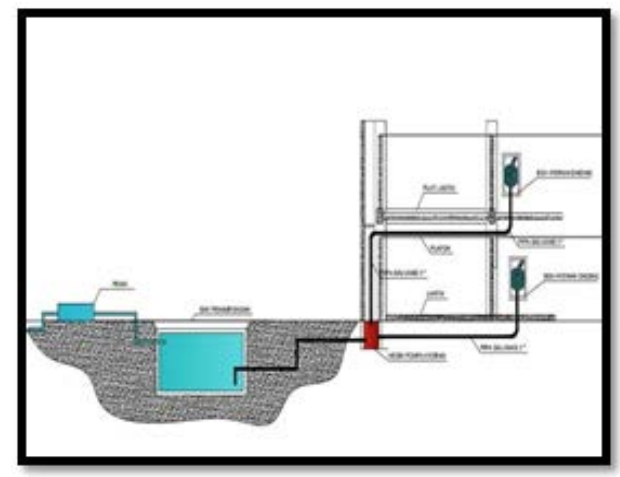

Gambar 8

Konsep Utilitas Hydrant Dinding

(Sumber : Penulis, 2017)

Konsep hydrant dinding atau alat pemadam kebakaran emergency diletakan pada bagian ruangan yang dapat dijangkau seperti selasar, lobby, dan ruang kegiatan umum lainya serta dibedakan mesin pemompanya dari mesin pompa lainya tujuanya adalah memaksimalkan tekanan air.

Konsep Utilitas Sprinkler

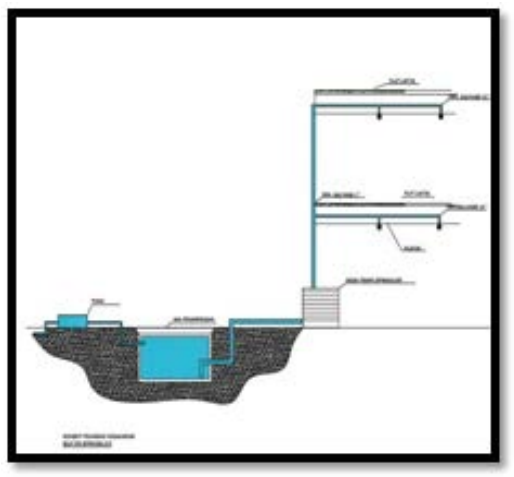

Gambar 9

Konsep Utilitas Sprinkler

(Sumber : Penulis, 2017)

Konsep utilitas sprinkler ialah dilatekan di setiap kamar inap tujuannya agar mencegah kebakaran secara cepat karena pada suhu kamar tertentu alat ini akan menyemprotkan air secara otomatis, dan dibedakan pompanya dari pomba air lainya tujuannya adalah memaksimalkan tekanan air. 
Nur Husniah Thamrin, Hatta Musthafa Adham Putra, Paskalis, Perencanaan Mahakam Boutique Hotel di Samarinda Penekanan Pada Tata Ruang Dalam

Konsep Smoke Detector

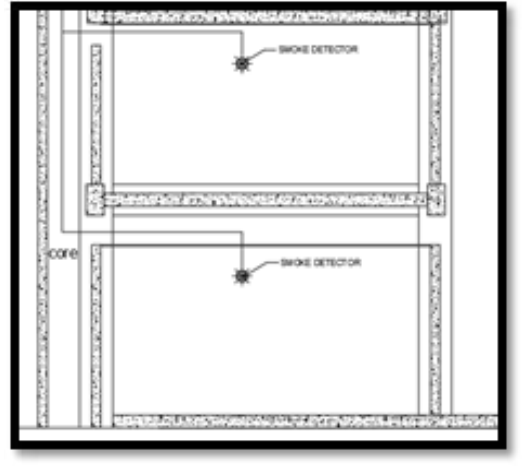

Gambar 10

Konsep Utilitas Smoke Detector (Sumber : Penulis, 2017)

Konsep Smoke Detector merupakan salah satu utilitas penunjang yang penting bagi sebuah hotel, karena dapat menciptakan kehigenisan dan kenyamanan di dalam kamar terutama penghawaan dalam suatu ruangan, kerena apa bila alat tersebut sudah terpasang maka setiap pengunjung segan untuk melakukan atau merokok di sembarang tempat, dan pengunjung dapat dengan tertib berkunjung.

\section{KESIMPULAN DAN SARAN \\ 4.1. KESIMPULAN}

Berdasarkan dengan hasil perancangan dan pembahasan yang telah disusun, maka dapat disimpulkan bahwa Mahakam Boutique Hotel di Samarinda merupakan bangunan hotel yang menyediakan berbagai macam fasilitas. Mahakam Boutique Hotel mengambil gaya arsitektur Vernakular (Lamin Dayak) pada bagian eksterior, baik dari segi warna, maupun bentuknya. Pada bagian interior juga menganut gaya klasik Kalimantan namun dipadukan dengan gaya yang lebih modern.

Selain itu, Mahakam Boutique Hotel juga menekankan pada (TRD) Tata Rruang Dalam, yaitu Penghawaan dan pencahayaan. Penghawaan dirancang sedemikian rupa agar Mahakam Boutique Hotel tampak lebih nyaman. Pencahayaan juga sangat diperlukan untuk menampak efek tertentu dalam ruangan.

Kelebihan dari Mahakam Boutique Hotel ini sendiri selain menyediakan berbagai fasilitas dan pelayanan yang sulit ditemukan di Samarinda, juga dari gaya arsitekturnya yang jarang ditemui di Samarinda sehingga pengunjung dapat merasakan pengalaman baru yang berbeda dari tempat-tempat lainnya. Selain itu pemilihan warna-warna mencolok yang ceria mulai dari eksterior maupun interiornya diharapkan dapat memberikan dampak psikologis yang positif bagi pengunjungnya.

\subsection{SARAN}

Beberapa saran-saran untuk mengembangkan perancangan ini adalah sebagai berikut :

- Perancangan sebuah bangunan tidak boleh hanya terpaku dengan apa yang disampaikan dalam perkuliahan, namun masih banyak pelajaran yang dapat diambil jika kita mau mengeksplor lebih dalam, salah satunya melalui internet dan buku.

- Dalam perancangan sebuah bangunan juga harus memperhatikan faktor pengunjung maupun penghuni bangunan sehingga pengunjung maupun penghuni dapat merasa nyaman dan betah, dengan begitu fungsi bangunan dapat dimanfaatkan dengan sebaik-baiknya.

Semoga laporan tugas akhir ini dapat bermanfaat serta memberi inspirasi bagi yang membacanya. 


\section{DAFTAR PUSTAKA}

Badan Pengembangan dan Pembinaan Bahasa (2012). Definisi Hotel. https:// Kamus Besar Bahasa Indonesia ( KBBI ) versi online. 22 Februari 2017 jam 20.00.

Tanggoro, Dwi. Utilitas bangunan. UI Press. Jakarta.

Wikimedia (2012). Sejarah Arsitektur Dayak. https://en.wikipedia.org/wiki. 19 Juli 2017 jam 21.00 .

Wikimedia (2017). Jumlah penduduk kota Samarinda. http;//en.Wikipedia.org/wiki/Kota Samarinda. 20 Februari 2017, jam 23.00.

Wordpress, 2016. peranan dan fungsi hotel. perhotelan.web.id. 9 Agustus 2017 jam 21. 40 
Nur Husniah Thamrin, Hatta Musthafa Adham Putra, Paskalis, Perencanaan Mahakam Boutique Hotel di Samarinda Penekanan Pada Tata Ruang Dalam

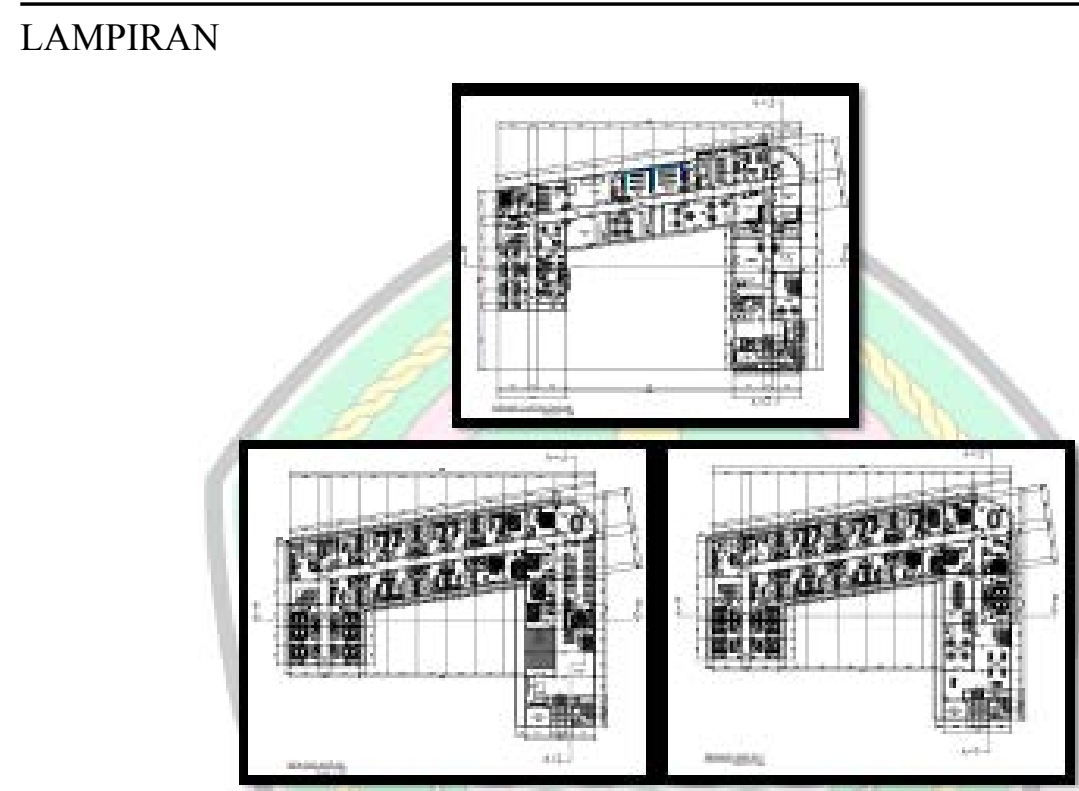

Gambar 11. Denah

(Sumber : Penulis, 2017)
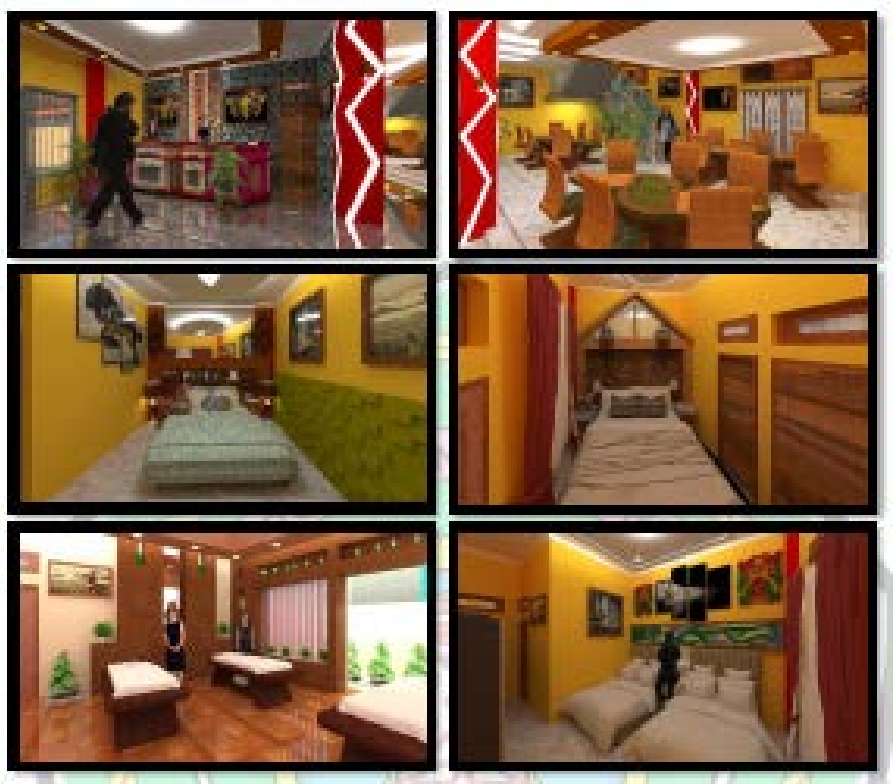

Gambar 12. Interior

(Sumber : Penulis, 2017)
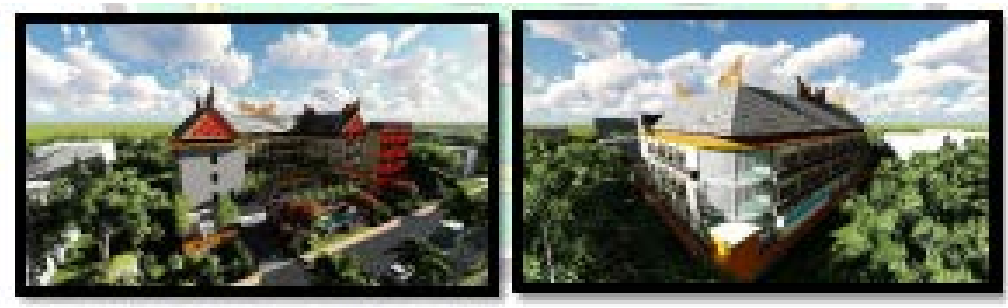

Gambar 13. Eksterior

(Sumber : Penulis, 2017) 